\title{
Reforming the 1983 Mental Health Act
}

\author{
Tony Hope Editorial Associate, fournal of Medical Ethics
}

A "Scoping Study Committee" has been established to advise the government on reform of the 1983 Mental Health Act (MHA). This provides a valuable opportunity for addressing, among other issues, the problem of discrimination against those with mental disorder.

People with mental disorder are discriminated against in two quite different ways. Consider $\mathrm{Mr} \mathrm{A}$ and $\mathrm{Mr} \mathrm{B}$, both of whom have been seriously violent. $\mathrm{Mr} \mathrm{A}$ is not mentally ill. He serves a prison sentence. $\mathrm{He}$ is still a danger to others, but having served his sentence he cannot be further detained. $\mathrm{Mr} \mathrm{B}$ suffers from a mental disorder. He is placed in a secure psychiatric hospital. As long as he is thought to pose a risk to others he continues to be detained. Thus, of two people, both equally dangerous, the one who has a mental disorder can be locked in a secure institution indefinitely in order to protect others. The one who is not mentally disordered is free once he has served his sentence.

Consider now $\mathrm{Mr} \mathrm{C}$ and $\mathrm{Mr} \mathrm{D}$. Mr C is physically ill, but he is not suffering from a mental disorder. $\mathrm{He}$ is refusing beneficial treatment. Without treatment, he may come to serious harm. However, he has the capacity to refuse treatment. The legal situation is clear: an adult with legal capacity may refuse any (even life-saving) treatment. Mr D, on the other hand, is suffering from a mental disorder, but he retains the common law capacity to refuse treatment. Like $\mathrm{Mr} \mathrm{C}, \mathrm{Mr} \mathrm{D}$ is refusing beneficial treatment for his mental disorder. Mr D's common law right to refuse treatment, however, may be overridden under the 1983 Mental Health Act. Under current law, the surgeon has to stand by while his or her patient, who has capacity to refuse treatment bleeds to death. The psychiatrist, on the other hand, can intervene, ignoring his patient's competent refusal, to prevent much lesser harm. Why this double standard?

This is not simply a theoretical issue as is shown by the case of $\mathrm{B} v$ Croydon District Health Authority. ${ }^{1}$ This case concerned a 24-year-old woman who had been admitted to psychiatric hospital with a diagnosis of borderline personality disorder, and who had a history of self-harm. She was detained under the 1983 Mental Health Act following her attempts to cut and hurt herself. In hospital she was prevented from carrying out such harmful behaviour, but her response was virtually to stop eating and, as a result, her weight fell to a dangerously low level. Eventually, her doctors considered her to be within a few months of death, and sought an injunction to tube feed her compulsorily. The High Court decided two points: first, that she had (common law) capacity to refuse treatment; and second, that despite this, she could be compulsorily treated under the 1983 Mental Health Act.

In a paper which deserves much wider recognition, Szmuckler and Holloway ${ }^{2}$ argue that the 1983 Mental Health Act should be done away with altogether. Whether or not this is right, any reform of the 1983 Mental Health Act should start with a consideration of the key issues, and determine the best ways of dealing with these issues. These best ways may be facilitated by specific legislation which amounts to a reformed MHA, but this should not be presumed.

It might be argued that mental disorder-at least of a nature or degree which makes it appropriate for the patient to receive treatment in hospital (the current criterion in the MHA)automatically means that the patient lacks capacity to refuse treatment. Even were this the case, lack of capacity should be an explicit condition for compulsory treatment in order to normalise the management of those with mental disorder. But it manifestly is not the case. The concepts of mental disorder and incapacity are quite different and there is no logical reason why mental disorder should entail incapacity. Furthermore, as the case of $B$ v Croydon Health Authority ${ }^{1}$ shows, they are not empirically equivalent.

To justify the double standard, one would need to argue that mental disorder provides a reason, independently of capacity, for overriding a patient's refusal of beneficial treatment. The reason 
cannot be the degree of harm that results from treatment refusal-for this can be as great for the Jehovah's Witness. The reason must be to do with the mental illness affecting the decision. I imagine that those who would defend the "double standard" have the following kind of case in mind. ${ }^{3}$

$\mathrm{Mr} \mathrm{E}$ is depressed. He does not believe that life is worth living. $\mathrm{He}$ is thinking seriously of killing himself. $\mathrm{He}$ accepts that how he feels now is different from how he used to feel. He accepts that this could be called depression and that treatment might return him to his old self. He has no delusions or hallucinations, neither is he suffering from marked psychomotor retardation. Since $\mathrm{Mr}$ $\mathrm{E}$ is able to understand and believe the facts, and is not intellectually impaired, he might be regarded as having the capacity to refuse treatment for mental disorder. And yet it would be wrong to let him commit suicide because his depression - his mental disorder - has affected his judgment. Thus, it would seem that the mental disorder itself provides grounds for overriding $\mathrm{Mr}$ E's competent refusal of hospital admission and treatment.

Whilst I agree that it might be right to treat $\mathrm{Mr}$ E despite his refusal, the grounds for this, in my view, are that $\mathrm{Mr} \mathrm{E}$ lacks capacity. An analysis of capacity purely in terms of intellectual functioning is too narrow. If a mental disorder leads to changes in a person's values, and it is these changes which underlie the refusal of beneficial treatment, then the person lacks capacity to refuse treatment. Adopting this broad approach to incapacity is not the same as accepting that mental disorder as such can be grounds for overriding refusal of treatment for the mental disorder. This is for two reasons. First, in order to justify overriding refusal there must be good reason to believe that the refusal results from the disorder. Second, if this broad approach to incapacity is the right approach in the case of refusal of treatment for mental disorder, it is the right approach in the case of refusal of treatment for physical disorder, and it should be incorporated into common law.

The political concern around limiting compulsory detention to those who lack capacity will be focused more on dangerousness to others than on the patient's own best interest. The key issue is: when is it right compulsorily to detain someone who poses a risk to other people? In answering this question, there should be no presumption that the conceptual and legal framework be similar to that required for when a patient is refusing beneficial treatment.
What is it that justifies letting $\mathrm{Mr} \mathrm{A}$ go frees (after he has served his sentence) but keeping the mentally disordered $\mathrm{Mr} \mathrm{B}$ under compulsor detention indefinitely? If the sole grounds for detaining $\mathrm{Mr} \mathrm{B}$ are that he continues to pose $\overline{9}$ high risk to others, then we should be prepared to detain $\mathrm{Mr}$ A. But to detain $\mathrm{Mr}$ A beyond h $\$$ prison sentence would fall foul of English ans European Law. Perhaps it is easier to predict rista and perhaps the risk is greater in the case of ment tally disordered people who have been violent; but if these facts (if they are facts) provide acceptabe grounds for indeterminate detention of some peco ple with mental disorder, then they providie grounds for detaining a person without mentạt disorder if the degree of predictable risk of harrif to others is as great. A more plausible justificatiog for the indeterminate detention of $\mathrm{Mr} \mathrm{B}$ is that, when well, he may agree that it is right to detaig him whilst he is ill and dangerous to others. I seems doubtful, however, that this justification is sufficient in all relevant situations. After all, $\mathrm{Mr} \mathrm{B}$ may not so agree.

I suspect that if we start with the question "wha should be the legal framework for compulsory detention and treatment of those with mental dis order?" we will continue to deal unjustly with the mentally ill. Our starting point should bo questions such as what framework (legal and com ceptual) should we have for treating a patien against his will and in his own best interests, and what framework should we have for protecting the public from dangerous people. Mental disorder will affect relevant concepts (such as capacity and responsibility), but it should not be the point off departure.

\section{Acknowledgement}

I would like to thank Dr Nigel Eastman for help? ful discussion on issues raised in this editorial.

Tony Hope is Editorial Associate of the Journal of Medical Ethics, a Psychiatrist and Reader in Medion cine and Leader, Oxford Practice Skills Projec⿷ Oxford University, UK.

\section{References}

1 B v Croydon Health Authority (1995) 1 All ER 683

2 Szmuckler G, Holloway F. Mental health law is now a harmf anachronism. Psychiatric Bulletin 1998; 22:662-5.

3 Hope T, Eastman N. The likely clinical and ethical implication of introducing an incapacity test into a new mental health acf (Submitted for publication, 1999.) 